\title{
Neurogenic Pulmonary Edema Developing After Cesarean Section
}

\author{
Handan Güleç ${ }^{1}$, Münire Babayigit ${ }^{2}$, Aysun Kurtay ${ }^{2}$, Zehra Tutal ${ }^{3}$, Necla Dereli $^{2}$, Saziye Sahin ${ }^{4}$, \\ Eyup Horasanli ${ }^{1}$
}

${ }^{1}$ Yildırım Beyazit University

Ankara - Turkey

${ }^{2}$ Kecioren Training and

Research Hospital Ankara -

Turkey

${ }^{3}$ Ufuk University Ankara -

Turkey

${ }^{4}$ Gazi University Ankara -

Turkey

\section{Corresponding Author:}

Dr. Handan Güleç

\section{Address:}

Yıldırım Beyazit University

Tel: 905056725948

\section{E-mail:}

handandrhandan@yahoo.com.tr

Başvuru Tarihi/Received : 21-07-2014

Kabul Tarihi/Accepted:

14-10-2014

\begin{abstract}
Neurogenic pulmonary edema (NPE) is a pathogenesis of pulmonary edema which occurs often in the early period following the acute neurologic changes affecting the central nervous system and proceeds with respiratory failure. It causes respiratory problems requiring intubation in the patient. When evaluated in general terms, the pathophysiology of NPE includes cardiopulmonary dysfunction caused by catecholamines that are secreted rapidly and abundantly. This case study will examine the respiratory failure of a 35-year-old pregnant (for 37 weeks), which developed after an emergency cesarean section, and her later being diagnosed with Arteriovenous Malformation (AVM).
\end{abstract}

Key words: Arteriovenous Malformation ,cesarean section 


\section{DOI: $10.16899 /$ ctd.89553}

\section{INTRODUCTION}

Neurogenic pulmonary edema (NPE) is a pathogenesis of pulmonary edema which occurs often in the early period following the acute neurologic changes affecting the central nervous system and proceeds with respiratory failure. (1) It causes respiratory problems requiring intubation in the patient. The most important part of diagnosis is to realize the situation.(2) NPE occurs after cases such as spinal cord injury, subarachnoid hemorrhage, traumatic brain injury, intracranial hemorrhage, status epilepticus, subdural hematoma, etc..(3) When evaluated in general terms, the pathophysiology of NPE includes cardiopulmonary dysfunction caused by catecholamines that are secreted rapidly and abundantly. (4)

This case study will examine the respiratory failure of a 35-year-old pregnant (for 37 weeks), which developed after an emergency cesarean section, and her later being diagnosed with Arteriovenous Malformation (AVM).

\section{CASE}

A 35 years old pregnant (for 37 weeks) was received into the operating room for emergency caesarean section due to fetal distress. It was clarified that chronic lung disease or drug allergy was not involved in her medical history. After taking informed patient consent, spinal anesthesia was chosen because her hunger period was not sufficient for general anesthesia. While she was in sitting position, 10 $\mathrm{mg}$ hyperbaric bupivakain was injected intratechally with a 25-gauge spinal needle through the L3-4 intervertebral space. The operation was started when the sensory block level reached T4. The patient, whose hemodynamic and respiratory parametres were stable during the *Manuscript (excluding Author Identifiers) intraoperative period, was received into recreation room with her healthy newborn. And then, the patient was transferred to obstetrics and gynecology clinic.

In the neurologic examination of the patient, who had some complaints such as dizziness, weakness, and sensory loss at her left leg in the first postoperative day; a loss of power and sense at lower extremities (1/5) and incontinence was observed. Hydrosyringomyelia and a $17 \times 22 \mathrm{~mm}$ mass at level of T1-2 were found in her contrast lumbar and thorocal MRI.
Neurosurgeon started the administration of 250 $\mathrm{mg}$ dexamethasone four times a day via the parenteral route. As respiratory distress and the Cheyne Stokes respiration developed in the patient together with the deterioration of her general condition at the end of the second day after the operation, she was accepted to the Intensive Care Unit (ICU). When her arterial blood gas values were observed to be $\mathrm{pH}: 7,12$, pCO2:70, pO2:55 in her first examination in ICU, the patient was intubated with $2 \mathrm{mg} / \mathrm{kg}$ propofol and $1 \mathrm{mg} / \mathrm{kg}$ succinylcholine, and mechanical ventilation was started. Continuous infusion of propofol was administered for sedation at a dose of $0.5 \mathrm{mg} / \mathrm{kg}$. As a 'ground glass' image and findings of strain were determined in the pulmonary $\mathrm{x}$-ray graph taken in her bed in ICU, furosemide administration was started with a dose of $0.3-0.5 \mathrm{mg} / \mathrm{kg}$. Her respiratory parameters were taken under control after the administration of furosemide for approximately seven days, and the mechanical ventilation was stopped as her arterial blood gas values were calculated as $\mathrm{pH}: 7,45, \mathrm{pCO} 2: 36$, pO2:105. We learned that the patient, who was transferred to a university hospital's neurosurgery clinic in order to operate the previously found spinal mass, was operated with a diagnosis of arteriovenous malformation $(\mathrm{AVM})$ and later discharged in good health. We also reached the information that NPE did not develop during this operation period.

\section{DISCUSSION}

NPE, which should be considered in hypoxia and lung edema evidence after a neurological disorder because of unspecific diagnostic criteria, is a much more common situation than it is thought(4). And as for our patient, despite the fact that there wasn't any neurologic situation which showed any symptom or evidence, it was triggered by spinal anaesthesia application. Although the pathogenesis could not be fully understood, the mediators, which were released due to the intracranial pressure changes, are thought to be developed as a result of the changes in the pulmonary vascular area (5).

In our case, we consider that NPE developed depending on the release of mediators increasing the pressure of cerebrospinal (CSF) fluid, under the influence of AVM in thoracal area, as well as the intrathecal administration of 


\section{DOI: $10.16899 /$ ctd.89553}

$10 \mathrm{mg}$ hyperbaric bupivacaine through the lumbar region of the spinal cord. While making a diagnosis of NPE, other causes such as leftventricular congestive heart failure and aspiration pneumonia should be dismissed through differantial diagnosis. Although the mechanism of NPE is not known exactly, there are two theories.

1- Increase of pulmonary capillary membrane permeability

2- Increase of pulmonary vascular hydrostatic pressure (3).

The two most important reasons for the increase of the pulmonary capillary endothelium permeability are the direct mechanical damage and direct neuronal effect on the capillary endothelium(3). Having studied the related role of nervous activity, Thedore and Robinblast suggested that neural induction gave damage to the endothelium through the increase of intravascular pressure, and the protein-rich plasma leaked out into the interstitial space and alveolar surface(6). What supports this theory is that high intravascular pressure is observed to cause damage to pulmonary capillary area(7). Meanwhile, in our case, an increase of intravascular pressure after the cesarean section was not observed. Our idea is that, AVM in thorocal site of spinal cord and the increase of pressure due to the local anesthetic given for spinal anesthesia caused NPE. Patients who are diagnosed with NPE, should not have cardiac problems especially such as congestive heart failure. . In our case, the patient was a healthy young adult woman and she didn't have any cardiac complaint during her pregnancy and delivery periods. In addition, her cardiac enzymes and ECG results that were tested during the intensive care period were evaluated as within the normal range. Although QT prolongation in ECG is observed in patients with subarachnoid hemorrhage, our case didn't have any ECG changes(8). The reason for pulmonary edema which occurs at normal cardiac pressure level is not exactly known. It is suggested that, it can depend on hydrostatic pressure increase and pulmonary venoconstriction(9). It is shown that dogs which are experimantally affected by intracranial hypertension develop hydrostatic edema as a result of the constriction of pulmonary veins (8). In an isolated lung model of another experimental study, the increase of pulmonary blood flow resistance and pressure is accompanied by an increase of intracranial pressure (10). The increase of resistance due to venoconstriction causes the level of cathecolamine and especially epinephrine to rise (11). In our case, we didn't measure the level of epinephrine. The induction of pulmonary venoconstriction increases capillary pressure, and leads to the occurrence of hydrostatic edema. Despite the increase of pressure in pulmonary vein, the pressure of pulmonary artery is observed to be normal or even low.

\section{CONCLUSION}

The pulmonary edema developing after a sudden neurologic phenomenon is called as NPE. In our case, NPE developed due to the spinal anesthesia during the cesarean operation of our pregnant patient with an unknown AVM. - This case should be considered for patients with respiratory distress which develops after spinal anesthesia and has unknown reasons.

\section{REFERENCES}

1. Simon RP. Neurogenic Pulmonary Edema. Neurol Clin 1993;11:309-23.

2. Lakkireddigari SK, Durga P, Nayak M, Ramchandran G. Preoperative Neurogenic Pulmonary Edema: A Dilemma for Decision Making. J Anaesthesiol Clin Pharmacol. 2012 Apr;28(2):232-4.

3. Davison DL, Terek M, Chawla LS. Neurogenic Pulmonary Edema. Crit Care. 2012 Dec 12;16(2):212.

4. Solenski, et al. Medical Complications of Aneurysmal Subarachnoid Hemorrhage: A Report of the Multicenter, Cooperative Aneurysm Study. Participants of the Multicenter Cooperative Aneurysm Study. Crit Care Med 1995;23:1007-17.

5. Mayer SA, FinkME, HommaS, etal. Cardiac Injury Associated with Neurogenic Pulmonary Edema following Subarachnoid Hemorrhage. Neurology 1994;44: 815-20.

6. Theodore J,Robin ED. Speculations on Neurogenic Pulmonary Edema(NPE). Am Rev Respir Dis 1976;113:405-11

7. West JB. Stress Failure of Pulmonary Capillares: Role in Lung and Heart Disease. Lancet 1992;340:762-67.

8. Samuels MA. Neurally Induced Cardiac Damage: Definition of the Problem. Neurol Clin 1993;11-273-92.

9. Smith WS, et al. Evidence for a Hydrostatic Mechanism in Human Neurogenic Pulmonary Edema. Chest 1997; 111:1326-33.

10. Maron MB, DawsonCA. Pulmonary Venoconstriction Caused by Elevated Cerebrospinal Fluid Pressure in the Dog. J Appl Physiol 1980;49:73-8.

11. Maron MB. Pulmonary Vasoconstriction in a Canine Model of Neurogenic Pulmonary Edema. J Appl Physiol 1990;68:912-18. 